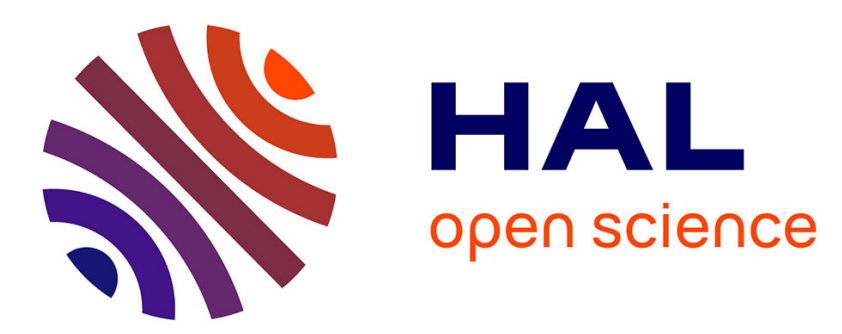

\title{
Does size matter? The impact of caseload and expertise concentration on AMI 30-day mortality-A comparison across 10 OECD countries
}

Benoît Lalloué, Michael Padget, Etienne Minvielle, Niek Klazinga, Ian Brownwood

\section{To cite this version:}

Benoît Lalloué, Michael Padget, Etienne Minvielle, Niek Klazinga, Ian Brownwood. Does size matter? The impact of caseload and expertise concentration on AMI 30-day mortality-A comparison across 10 OECD countries. Health Policy, 2019, 123 (5), pp.441-448. 10.1016/j.healthpol.2019.03.007 . hal-02089667

\section{HAL Id: hal-02089667 https://hal.science/hal-02089667}

Submitted on 4 Apr 2019

HAL is a multi-disciplinary open access archive for the deposit and dissemination of scientific research documents, whether they are published or not. The documents may come from teaching and research institutions in France or abroad, or from public or private research centers.
L'archive ouverte pluridisciplinaire HAL, est destinée au dépôt et à la diffusion de documents scientifiques de niveau recherche, publiés ou non, émanant des établissements d'enseignement et de recherche français ou étrangers, des laboratoires publics ou privés. 


\title{
Does size matter? The impact of caseload and expertise concentration on AMI 30-day mortality - A comparison across 10 OECD countries
}

Benoît Lalloué, PhD; EA 7348 MOS-EHESP, Gustave Roussy 114, rue Édouard-Vaillant 94805 Villejuif, France; benoit.lalloue@gustaveroussy.fr

Michael Padget, PhD; Health Division, Directorate for Employment, Labour and Social Affairs, OECD; michael.padget@oecd.org

Ian Brownwood, MHM; Health Division, Directorate for Employment, Labour and Social Affairs, OECD; ian.brownwood@oecd.org

Etienne Minvielle, PhD, MD; I3-Research Management Center, Polytechnique School, CNRS, France; etienne.minvielle@gustaveroussy.fr

Niek Klazinga, PhD, MD; Health Division, Directorate for Employment, Labour and Social Affairs, OECD; Niek.KLAZINGA@oecd.org

Acknowledgements: none

Conflict of Interest: none

DOI: https://doi.org/10.1016/j.healthpol.2019.03.007

Editor version: https://www.sciencedirect.com/science/article/pii/S0168851019300533

\begin{abstract}
Objective: To examine the variability of hospital performance within and across countries, using 30-day acute myocardial infarction (AMI) mortality, and to study the impact of hospital characteristics on performance.
\end{abstract}

Study setting: Hospital-level adjusted risk standardized mortality rates (RSMR) and hospital characteristics were collected from 10 OECD countries 10 and two collaborating countries including 1,163 hospitals. Rates were based on AMI admissions between 2013 and 2015. 
Study design: Associations between RSMR and hospital characteristics were studied using univariate and multivariate linear regressions. Clusters of hospitals were created using hierarchical clustering and mortality compared using linear regression.

Findings: Wide variation between countries was found for RSMR and hospital characteristics. Regression models showed large country effects. A high volume of AMI admission was associated with lower RSMR in a model using a restricted number of hospital characteristics $(-0.83, \mathrm{p}<0.001)$ but not in a model using all characteristics $(-1.03, \mathrm{p}=0.06)$. Analysis within countries supported this association. Hospital clusters showed clear differences in characteristic distributions but no difference in RSMR.

Conclusions: The effect of volume may support policies toward a concentration of services within the hospital sector. The effect of other hospital characteristics was inconclusive and suggests the importance of system-wide characteristics or pathways of care (i.e. timeliness and nature of initial response and during transportation to a hospital, transfers between hospitals, post-discharge organization) in explaining variation.

\section{Highlights:}

- Wide variation between countries was found for RSMR and hospital characteristics.

- High volume of AMI admission was associated with lower RSMR.

- Within countries analysis supported this association.

- Hospital clusters showed no significant difference in RSMR.

Keywords: hospital performance; international comparison; AMI mortality; hospital characteristics 


\section{Introduction}

Hospital performance is a key aspect of health systems and an important target in national efforts to improve overall system performance [1,2]. The Organization for Economic Cooperation and Development (OECD) currently publishes a number of hospital performance-related indicators on the national level. These indicators are used by member countries for a range of policy objectives including: public accountability and transparency, benchmarking and quality improvement, standard setting and compliance, and governance and management performance assessment $[3,4]$.

The 30-day mortality rate for acute myocardial infarction (AMI) is one key OECD hospital performance measure used to understand performance across countries. Overall rates of 30day AMI mortality have decreased in recent years in many countries but some large variation continues to exist at the national and hospital-level [5]. Indeed, health care quality indicators at a national level can mask important within-country variations in hospital performance [6]. Understanding hospital-level variation including its main drivers is important to implement policy responses to reduce variation and in improving performance.

A number of national studies have examined hospital variation in 30-day AMI mortality through the role of various hospital characteristics. Hospital size, academic status, ownership type, and location among other characteristics have been shown to be important factors in explaining variation in some studies. [7-10]. Debate remains however about the impact of these characteristics. For example Bradley et al. found significant associations between 30day AMI mortality and academic status, number of hospital beds, AMI volume, cardiac facilities available, urban/rural location, geographic region, ownership type, and the socioeconomic status (SES) profile of patients. On the other hand, Krumholtz et al. found that hospital characteristics such as number of beds, ownership, academic status, and technical capacity were not key drivers of performance variation [11]. 
Interest has grown in recent years in moving beyond national studies to understanding hospital performance variation internationally. These data may provide additional insight into within country variations and allow for international hospital performance benchmarking as well as cross-country comparisons and learning opportunities. Significant methodological and scientific progress has been made in this area internationally through European studies of hospital performance and efficiency including the European Hospital outcomes, Performance and Efficiency project (http://www.eurohope.info/) and the European Collaboration for Healthcare Optimisation project (http://echo-health.eu/). Both studies rely on the collection of patient level data to undertake international comparisons and have developed methodologies for internationally comparable indicators of hospital performance and efficiency including 30day AMI mortality. Studies in European countries report differences in AMI outcome across countries and a relationship between volume and mortality $[12,13]$. However, these studies focus on one continent and on factor at a time.

Building on this international work, the OECD launched the hospital performance project in 2015 in order to better understand hospital performance across OECD countries and to increase international comparisons. This work mirrors much of the methodological foundations of ECHO and EuroHOPE, particularly given the lead researchers of these projects were members of the methodology expert group guiding the work. Key improvements include: providing a more feasible way of routinely collecting data from a wide range of countries without establishing data exchange agreements such as in the ECHO project, utilizing linked data to account for hospital transfers and deaths outside of the hospital like the ECHO project, and extending the scope of the project beyond Europe to other OECD countries. This project collected risk adjusted hospital-level 30-day AMI mortality at the hospital level along with hospital characteristics from participating countries. Participation in the project was voluntary and solicited from all OECD countries as well as from selected partner countries including 
Malta and Singapore. Project aims included broadening the availability of internationally comparable data on hospital performance and providing opportunities for performance benchmarking. The study also sought to better understand the hospital-level factors related to AMI mortality variability including the role of: hospital ownership, technical capacity, location, expertise, and volume. To our knowledge, this study is the first to bring together hospital-level data from multiple continents.

\section{Material and methods}

Risk standardized mortality rates (RSMR) for 30-day $\mathrm{AMI}^{1}$ mortality were computed from patient level data within each participating country and provided to the OECD at the hospital level. Data was received from 10 OECD countries including: Canada, Denmark, Finland, Israel, Italy, Korea, Latvia, Norway, Slovenia, and Sweden as well as two collaborating countries including Malta and Singapore. Rates were based on patient data aggregated across the years 2013-2015 and adjusted for age, sex, existence of complicating conditions (comorbidity) and previous AMI-admission and were calculated from national hospital administrative databases.

A linked-record approach to calculating RSMR was used within each country. This approach requires that a unique patient identifier be available for use across multiple administrative databases to allow for the linkage of hospital admissions within and across hospitals as well as to death registries. Using this approach, 30-day mortality was calculated as the number of patients dying within 30 days of admission to hospital for an AMI divided by the total number of patients admitted to the hospital for an AMI. In the case of a patient transferred to a second hospital following an initial AMI admission, death was attributed to the first hospital where

\footnotetext{
${ }^{1}$ AMI was defined using ICD-9-CM codes '4100', '4101', '4102', '4103', '4104', '4105', '4106', '4107', '4108', '4109' or ICD-10-WHO codes 'I210', 'I211', 'I212', 'I213', 'I214', 'I219', 'I220', 'I221', 'I228', 'I229'. Countries using coding systems other than ICD-9-CM or ICD-10-WHO were asked to use equivalent codes in their local system.
} 
admission occurred. In the case of multiple eligible admissions for a single patient, only the most recent admission was used for calculation purposes. Canadian hospital data was not fully linked to death registries meaning some deaths occurring outside of the hospital may not have been included in calculations.

A number of hospital characteristics were collected directly at the hospital level including: hospital ownership (government-owned/non-government owned), presence of a catheter lab (Y/N), location (urban/rural), academic status (Y/N) and the volume of AMI admissions over the observation period. Given variable data availability and definitions across participating countries, these hospital characteristics, defined as dichotomous variables, were selected as the most relevant and comparable for the purposes of this study.

A binary "high AMI" variable was created which identified the $25 \%$ of hospitals with the highest AMI caseload in each country as "high" regardless of the relative position with other countries. This definition was selected given the large variation of AMI volume between countries and based on the hypothesis that a hospital in a country with lower overall AMI volume per hospital might still acquire relatively more experience and expertise in treating patients than other lower-volume hospitals within the country. Based on this definition, a "high AMI" hospital in a country with low overall AMI admissions may have fewer AMI cases over the observation period than a non-"high AMI" hospital in a country with higher overall AMI admissions. This construction avoided attributing "high AMI" only to hospital in countries with higher overall AMI admissions and turning this variable into a mere proxy for a country effect.

783 hospitals with less than 50 AMI admissions over the observation period were excluded from analyses due to the extreme variability of RSMR in these hospitals. This threshold was chosen after sensitivity testing and consultation of the international expert group of the 
hospital performance project. Most of the excluded hospitals (768 (98\%) were located in

Canada, Italy or Korea), the remaining being located in Denmark, Latvia, Norway or

Slovenia. Within countries, excluded hospitals represented between $7.4 \%$ and $50.3 \%$ (28.9\%

on average) of the initial sample. The final sample was composed of 1,163 hospitals.

International data collection was performed using SAS software. Standard SAS code was provided to participating countries by the OECD and run on national hospital administrative data.

\section{Data analysis}

Associations between RSMR and the hospital characteristics were first evaluated independently using univariate regression for each hospital characteristic.

Next, two multiple linear regression models were used. The first model (named "all characteristics") used a country indicator and all five hospital characteristics as explanatory variables, without interaction terms ${ }^{2}$. The second model (named "restricted characteristics") included only the country indicator, high AMI volume, academic status and presence of a catheterization laboratory, with the 2-by-2 and triple interaction terms between the binary characteristics $^{3}$. The urban/rural and government owned characteristics were dropped from the second model due to heterogeneous definitions across countries and a general lack of nongovernment owned hospitals in the sample.

\footnotetext{
${ }^{2} \mathrm{RSMR}=\beta_{0}+\beta_{1} *($ High volume of AMI $=$ "Yes" $)+\beta_{2} *($ Catheterization laboratory $=$ "Yes" $)+\beta_{3} *$ $($ Academic $=" Y e s ")+\beta_{4} *($ Urban $=" Y e s ")+\beta_{5} *($ Government owned $=" Y e s ")+\sum \beta_{6 j} *$ $\left(\right.$ Country $=$ Country $\left._{j}\right)+\varepsilon$

${ }^{3} \mathrm{RSMR}=\beta_{0}+\beta_{1} *($ High volume of AMI $=$ "Yes" $)+\beta_{2} *($ Catheterization laboratory $=$ "Yes" $)+\beta_{3} *$ $($ Academic $=" Y e s ")+\sum \beta_{4 j} *\left(\right.$ Country $=$ Country $\left._{j}\right)+\gamma_{1} *($ High volume of AMI $=" Y e s ") *$ $($ Catheterization laboratory $=" Y e s ")+\gamma_{2} *($ High volume of AMI $=" Y e s ") *($ Academic $=" Y e s ")+\gamma_{3} *$ $($ Catheterization laboratory $=" Y e s ") *($ Academic $=" Y e s ")+\gamma_{4} *($ High volume of AMI $=" Y e s ") *$ $($ Catheterization laboratory $=" Y e s ") *($ Academic $=" Y e s ")+\varepsilon$
} 
Finally, in order to investigate the country-specific differences and further examine the effect of hospital characteristics, the second model (without country effects) was also run on all countries separately.

A sensitivity analysis on the coding of the AMI admission volume was completed by using the same regression models with AMI volume as a continuous variable, in global quartiles and by-country quartiles. Another sensitivity analysis was completed using hospital beds density terciles of countries instead of individual countries effects.

Multicollinearity was assessed using variance inflation factors (VIF).

To test the relationship of different hospital types with AMI mortality, clusters of hospitals based on distributions of the five hospital characteristics were created using hierarchical agglomerative clustering (HC). This unsupervised clustering method creates a hierarchy of clusters step by step, merging the closest clusters according to a given distance between categories at each step (more mathematical details are provided in supplementary material 1). Since the characteristics are both nominal and quantitative, the Gower distance was used to compute the dissimilarity matrix of the hospitals [14]. Mortality differences between clusters were tested using linear regression.

Data analysis was performed using the R 3.4 .1 software [15]. The risk alpha was set at $5 \%$ to assess the significance of the differences and results.

\section{Results}

\section{Descriptive statistics}

Average RSMR was 9.06 per 100 AMI admissions across all countries (standard deviation:

3.20). Country level average RSMR ranged from 8.03 in Canada to 18.23 in Malta. By country RSMR distribution is shown in Figure 1. RSMR of hospitals with fewer than 50 AMI 
admissions (excluded from main analysis) ranged from 0 to 447.11, with an average of 17.29 and a standard deviation of 36.73 .

(include Figure 1 here)

Results for hospital characteristics showed wide variability across countries (Table 1). The proportion of hospitals with a catheterization laboratory varied from $12 \%$ (Norway) to $100 \%$ (Finland and Korea), the proportion of urban hospitals varied from 9\% (Sweden) to 100\% (Malta, Singapore, Slovenia), and the proportion of academic hospitals ranged from $8 \%$ (Italy) to $100 \%$ (Israel). Only the proportion of government owned hospitals was consistently high across countries in the studied sample (93\% overall, from $42 \%$ (Israel) to $100 \%$ (Denmark, Finland, Latvia, Malta, Singapore, Slovenia)).

(include Table 1 here)

\section{Associations between RSMR and hospital characteristics}

In univariate analysis, only high volume of AMI $(-0.81,95 \%$ CI $(-1.23,-0.39), p<0.001)$ had a significant negative association with RSMR (supplementary material 2). When hospital characteristics were introduced in the first multivariate model (all variables), a significant association with RSMR was observed for high volume of AMI (-0.83, 95\% CI (-1.30, -0.36), p $<0.001)$ and government ownership $(1.08,95 \% \mathrm{CI}(0.31,1.85), \mathrm{p}=0.006)$. In the second model (restricted characteristics), only the high volume of AMI was borderline significant ($1.03,95 \% \mathrm{CI}(-2.13,0.06), \mathrm{p}=0.06)$. Other characteristics (presence of a catheter lab, location, and academic status) had no significant effect in either model, with particularly high associated p-values. Interaction terms were also not significant in model 2 (Table 2).

(include Table 2 here) 
Results for the sensitivity analyses on the AMI variable are available in supplementary material 3. Using AMI volume as a continuous variable, in global quartiles or by-country quartiles gave similar results for the model with all characteristics included. For the model with restricted characteristics, AMI volume had a significant effect (instead of borderline significant) in all sensitivity analyses. Catheterization laboratory and its interaction with AMI volume had a significant effect when AMI volume was used as a continuous variable.

Results for the sensitivity analyses using hospital beds density terciles are available in supplementary material 4. The effects of AMI volume, academic status, location and government ownership were similar to those already presented in both models. The presence of a catheterization laboratory was borderline significant in the model with restricted characteristic. Hospital beds density terciles were strongly significant in both models, with a positive association with RSMR for countries with a higher hospital bed density compared to countries with the lowest hospital beds density.

\section{Assessment of country effects}

In univariate analysis, country effects were significantly associated with RSMR (global p $<0.001$ ) (supplementary material 2). In multivariate analyses, with the exception of Canada, most countries showed significant positive effects on RSMR when compared to Italy in both models (Italy was used as reference since it was the country with the largest number of hospitals in the sample). The impact of the country effect on explaining variation across the global dataset was large. Both models had an adjusted- $\mathrm{R}^{2}$ of 0.22 , explained principally by the country effect (the same models without country effect had an adjusted-R $\mathrm{R}^{2}$ of 0.02 ).

Within country regressions analyses rarely showed significant results due in part to small sample sizes. However, in most countries, both the high volume of AMI and the presence of a catheter lab showed a non-significant negative relationship with RSMR (Table 3). 
(include Table 3 here)

\section{Hospital clusters}

We created five hospital clusters by applying HC on data (Table 4). Cluster 1 was composed of 470 hospitals with a small volume of AMI admissions (fewer than 235 AMI admissions on average over the observation period). These hospitals were non-academic, did not have catheterization laboratories, and were mostly government owned and rural. Cluster 2 was composed of 101 hospitals with characteristics similar to those of cluster 1 (small volume of AMI admissions -cluster average: 373-, non-academic, without catheterization laboratories, government owned) but with urban rather than rural hospitals. Cluster 3 was composed of 235 hospitals with the second highest volume of AMI admissions (cluster average: 787), which were government owned, rural, with catheterization laboratories and mostly non-academic. This cluster differs from cluster 1 and 2 by the presence of a catheterization laboratory as well as a higher volume of AMI admission. Cluster 4 was composed of 190 hospitals with a median volume of AMI admissions (cluster average: 577), a non-academic status, high presence of catheterization laboratories, and which were mostly urban and government owned (although the proportion of private hospitals is the highest in this cluster). This cluster differs from cluster 3 by its distribution of urban and private hospitals. Cluster 5 was composed of 167 hospitals with the highest volumes of AMI admissions, high academic status, and high presence of catheterization laboratories. These hospitals were also mostly government owned and urban.

(include Table 4 and Figure 2 here)

Despite strong differences in hospital cluster differentiation based on hospital characteristics, our analysis found no evidence for an association between our hospital clusters and RSMR (Table 4 and Figure 2). 


\section{Discussion}

This study shows important variations of AMI 30-day RSMR at the hospital level both between and within countries. These analyses were made possible through an international data collection with unprecedented scope and coverage. Overall, specific country effects explain a large part of the variability and a high AMI volume appears to be associated with lower mortality rates. The effect of the presence of a catheterization laboratory was inconclusive and no association was found between the academic status or the urban/rural location of hospitals and RSMR.

Our results are partly in line with other published studies. In 2010, Bradley et al. showed a lower AMI 30-day RSMR among academic and urban hospitals with a greater volume of AMI admission in the US, and in hospitals with open heart surgery capacity compared to hospitals with only catheterization laboratory or nothing [7]. Other studies have found an effect of greater volume in lowering RSMR but sometimes with a "volume threshold" after which increased volume did not result in lower mortality $[9,10,16]$. Analysis of our hospital data by volume strata suggested a similar volume threshold but differences between groups were non-significant. Other authors found reduced mortality among academic hospitals which was not reflected in our results $[8,11]$. Some questions remain about the effect of the ownership status as some studies found a reduced mortality in public hospitals [11] while others found increased mortality [10]. Our sample did not allow for this relationship to be sufficiently tested.

The negative correlation between AMI volume and RSMR may be explained in several ways. Hospitals with more AMI cases may have a staff with better experience and knowledge of good practices as well as specific and well-established organizational processes (both within the hospital and with other health professionals in the post-hospitalization phase) for AMI 
patients, which could improve survival [13]. Previous research has found a similar relationship between the number of cardiovascular procedures performed by a physician and short-term mortality [17], and between volume and surgical mortality [18,19]. Although small hospitals were not included in this study, their high average RSMR adds another indication of a volume effect. Our definition of high AMI may also play a role in interpreting this relationship. We selected the top volume hospital in each country regardless of the overall distribution. The relationship between high AMI and RSMR may therefore suggest a centralization of expertise and resources within each country regardless of the relative size internationally. The relationship between high AMI volume and lower RSMR within countries, while not statistically significant, may support this idea however this hypothesis remains speculative.

In multivariate models, presence of a catheterization laboratory showed no significant relationship with RSMR despite representing more advanced care capacity. Hospitals with a catheterization laboratory may admit more complex and/or severe AMI cases, which may explain some increase in mortality. However, most within-country analyses show a negative, although non-significant, effect of the catheterization laboratory. Taking into account additional characteristics (for instance ST-segment elevation myocardial infarction (STEMI) status) may help to explain these results.

The clusters constructed by hierarchical clustering are strongly differentiated on hospital characteristics; however, the absence of significant differences on mortality rates shows they are not sufficient to explain RSMR variations. Other classification methods, or other sets of characteristics, may give different results. Some studies have used hospital clusters as an explanatory variable for AMI RMSR, such as Bertomeu et al in Spain, who show a significant association between mortality and hospital clusters defined by the Spanish Ministry of Health and based on size, equipment, teaching activities, and complexity of care [20]. 
The construction of the RSMR indicator may play a role in our findings. Death in our calculation is attributed to the first hospital of admission even if a patient was transferred to and died in another hospital. This may have a variable effect on hospital mortality rates based on the relative proportion of transfer patients and the mortality rates of these patients $[21,22]$. Transfers within countries and care pathways can be dramatically different between countries which may affect RSMR and the relationship with hospital characteristics [23]. For example Norway has implemented a policy of care centralization (i.e. a small number of "reference centers" where patients are directed by "prehospital" services) in recent years which is reflected in the relatively low number of hospitals with catheter labs in our sample[24]. Other calculations for AMI-mortality exist which take a different approach to death attribution [12].

Our results showed a wide distribution of hospital characteristics which may be indicative of real differences across countries including aspects such as hospital financing, organization, and structure. Characteristic distributions may also be affected by the nature of data available to countries. For example, the high proportion of government owned hospitals in our dataset may reflect the greater availability of these data rather than a truly higher proportion across countries. This heterogeneity between countries could impact analyses in the sense that they no longer asses the characteristic's true effect, but a mixture between the true effect and the country effect. Adding country or system-level characteristics to future analyses could help address this issue.

The relatively small impact of hospital characteristics on mortality may highlight the importance of other within-hospital variables, such as organizational culture (treatment protocols, team organization) or team experience (generally and/or specifically for the catheterization laboratory) found to be important in other studies in addition to the physician experience $[25,26]$. This may also highlight the importance of some system level characteristics such as systems of transfers and care centralization. Initial research into these 
system level characteristics was carried out in 2017 by Moger et al. Researchers examined the differences in acute coronary syndrome mortality between Norway and Finland which have similar populations but different structures of care (decentralized in Finland with reduced emergency preparedness, centralized in Norway with large PCI departments). Results did not show a strong effect of organization variables such as distance to hospital, PCI hospital volume, and time to treatment among others [27].

To our knowledge, this is the first international analysis of the impact of hospital characteristics on AMI mortality rates of this scope and scale. However, our "global" results have to be qualified by the county-specific results, which show some heterogeneity between countries and are reflected in the large country effects in our models.

Our study has several limitations. Firstly, RSMR rates were not adjusted for STEMI status which is related to AMI treatment and the risk of mortality. This was due to highly variable STEMI coding quality and completeness across countries making adjustment unfeasible. Differences in secondary diagnosis coding depth were highly variable across countries which may also have an impact on adjustment by co-morbidity. Similarly, no complete information about timing of procedure was available which has been shown to have a large impact on survival [28]. On the country level, no information about the countries health systems, such as referral process, was available either. This information may help understand betweencountries differences. Inclusion of such data into subsequent analyses could help to address these issues.

Secondly, due to a lack of precision of certain hospital characteristics, data used in analyses may have been affected by different interpretations between countries. For example, no precise definition was provided for urban and rural categories and local country definitions were heterogeneous. 
Thirdly, due to data available in countries, our sample is mainly composed of government owned hospitals and may not be representative of all hospitals in a country.

Finally, small hospitals were excluded from analyses, although they represented about $40 \%$ of the initial sample and up to $50 \%$ of hospitals within individual countries. Additional work is planned to take into account these hospitals and their specificities.

\section{Conclusion}

AMI admission volume appears to have an important effect on the AMI RSMR, globally and in most of the countries studied. Rather than indicating absolute volume however, the definition of high AMI volume used in this study may suggest a link with the centralization of expertise and resources within each country. These results may support efforts for a concentration of services in the hospital sector however, as shown in other studies, further study is needed to better understand the complexities of this relationship. The effect of other hospital characteristics was less clear. Future research may be enhanced by evaluating characteristics of the health system and health care organization including assessing the whole pathway of AMI care.

Finally, more availability and comparability of data across countries, including patient and system level characteristics as well as medical practice recording, may allow a deeper understanding of the drivers of performance.

\section{References}

[1] Krumholz HM, Lin Z, Keenan PS, Chen J, Ross JS, Drye EE, et al. Relationship Between Hospital Readmission and Mortality Rates for Patients Hospitalized With Acute Myocardial Infarction, Heart Failure, or Pneumonia. JAMA 2013;309:587. doi:10.1001/jama.2013.333.

[2] Bucholz EM, Butala NM, Ma S, Normand S-LT, Krumholz HM. Life Expectancy after Myocardial Infarction, According to Hospital Performance. N Engl J Med 2016;375:1332-42. doi:10.1056/NEJMoa1513223. 
[3] Marshall MN, Shekelle PG, Leatherman S, Brook RH. The Public Release of Performance Data: What Do We Expect to Gain? A Review of the Evidence. JAMA 2000;283:1866-74. doi:10.1001/jama.283.14.1866.

[4] Rotar AM, van den Berg MJ, Kringos DS, Klazinga NS. Reporting and use of the OECD Health Care Quality Indicators at national and regional level in 15 countries. Int J Qual Health Care J Int Soc Qual Health Care 2016;28:398-404. doi:10.1093/intqhc/mzw027.

[5] Chung S-C, Sundström J, Gale CP, James S, Deanfield J, Wallentin L, et al. Comparison of hospital variation in acute myocardial infarction care and outcome between Sweden and United Kingdom: population based cohort study using nationwide clinical registries. BMJ 2015:h3913. doi:10.1136/bmj.h3913.

[6] OECD. Health at a Glance 2017: OECD Indicators. OECD; 2017. doi:10.1787/health_glance-2017-en.

[7] Bradley EH, Herrin J, Curry L, Cherlin EJ, Wang Y, Webster TR, et al. Variation in Hospital Mortality Rates for Patients With Acute Myocardial Infarction. Am J Cardiol 2010;106:1108-12. doi:10.1016/j.amjcard.2010.06.014.

[8] Navathe AS, Silber JH, Zhu J, Volpp KG. Does Admission to a Teaching Hospital Affect Acute Myocardial Infarction Survival? Acad Med 2013;88:475-82. doi:10.1097/ACM.0b013e3182858673.

[9] Ukawa N, Ikai H, Imanaka Y. Trends in hospital performance in acute myocardial infarction care: a retrospective longitudinal study in Japan. Int J Qual Health Care 2014;26:516-23. doi:10.1093/intqhe/mzu073.

[10] Han K-T, Kim SJ, Kim W, Jang S-I, Yoo K-B, Lee SY, et al. Associations of volume and other hospital characteristics on mortality within 30 days of acute myocardial infarction in South Korea. BMJ Open 2015;5. doi:10.1136/bmjopen-2015-009186.

[11] Krumholz HM, Merrill AR, Schone EM, Schreiner GC, Chen J, Bradley EH, et al. Patterns of Hospital Performance in Acute Myocardial Infarction and Heart Failure 30Day Mortality and Readmission. Circ Cardiovasc Qual Outcomes 2009;2:407-13. doi:10.1161/CIRCOUTCOMES.109.883256.

[12] Hagen TP, Häkkinen U, Belicza E, Fatore G, Goude F, on behalf of the EuroHOPE study group. Acute Myocardial Infarction, Use of Percutaneous Coronary Intervention, and Mortality: A Comparative Effectiveness Analysis Covering Seven European Countries: AMI, PCI, and Mortality. Health Econ 2015;24:88-101. doi:10.1002/hec.3263.

[13] Gutacker N, Bloor K, Cookson R, Gale CP, Maynard A, Pagano D, et al. Hospital Surgical Volumes and Mortality after Coronary Artery Bypass Grafting: Using International Comparisons to Determine a Safe Threshold. Health Serv Res 2017;52:863-78. doi:10.1111/1475-6773.12508.

[14] Gower JC. A General Coefficient of Similarity and Some of Its Properties. Biometrics 1971;27:857. doi:10.2307/2528823.

[15] R Core Team. R: A Language and Environment for Statistical Computing. Vienna, Austria: R Foundation for Statistical Computing; 2016.

[16] Ross JS, Normand S-LT, Wang Y, Ko DT, Chen J, Drye EE, et al. Hospital Volume and 30-Day Mortality for Three Common Medical Conditions. N Engl J Med 2010;362:1110-8. doi:10.1056/NEJMsa0907130.

[17] Vakili BA, Kaplan R, Brown DL. Volume-Outcome Relation for Physicians and Hospitals Performing Angioplasty for Acute Myocardial Infarction in New York State. Circulation 2001;104:2171-6. doi:10.1161/hc3901.096668.

[18] Birkmeyer JD, Stukel TA, Siewers AE, Goodney PP, Wennberg DE, Lucas FL. Surgeon volume and operative mortality in the United States. N Engl J Med 2003;349:2117-27. doi:10.1056/NEJMsa035205. 
[19] Peterson ED, Coombs LP, DeLong ER, Haan CK, Ferguson TB. Procedural volume as a marker of quality for CABG surgery. JAMA 2004;291:195-201. doi:10.1001/jama.291.2.195.

[20] Bertomeu V, Cequier Á, Bernal JL, Alfonso F, Anguita MP, Muñiz J, et al. In-hospital Mortality Due to Acute Myocardial Infarction. Relevance of Type of Hospital and Care Provided. RECALCAR Study. Rev Esp Cardiol 2013;66:935-42. doi:10.1016/j.rec.2013.06.006.

[21] Barbash IJ, Zhang H, Angus DC, Reis SE, Chang C-CH, Pike FR, et al. Differences in Hospital Risk-standardized Mortality Rates for Acute Myocardial Infarction When Assessed Using Transferred and Nontransferred Patients. Med Care 2017;55:476-482. doi:10.1097/MLR.0000000000000691.

[22] Samadashvili Z, Hannan EL, Cozzens K, Walford G, Jacobs AK, Berger PB, et al. Assessing Hospital Performance for Acute Myocardial Infarction: How Should Emergency Department Transfers Be Attributed. Med Care 2015;53:245-252. doi:10.1097/MLR.0000000000000305.

[23] OECD. Cardiovascular Disease and Diabetes: Policies for Better Health and Quality of Care. OECD Publishing; 2015. doi:10.1787/9789264233010-en.

[24] Magnussen J, Hagen TP, Kaarboe OM. Centralized or decentralized? A case study of Norwegian hospital reform. Soc Sci Med 2007;64:2129-37. doi:10.1016/j.socscimed.2007.02.018.

[25] Curry LA, Spatz E, Cherlin E, Thompson JW, Berg D, Ting HH, et al. What distinguishes top-performing hospitals in acute myocardial infarction mortality rates? A qualitative study. Ann Intern Med 2011;154:384-90. doi:10.7326/0003-4819-154-6201103150-00003.

[26] Bradley EH, Curry LA, Spatz ES, Herrin J, Cherlin EJ, Curtis JP, et al. Hospital strategies for reducing risk-standardized mortality rates in acute myocardial infarction. Ann Intern Med 2012;156:618-26. doi:10.7326/0003-4819-156-9-201205010-00003.

[27] Moger TA, Häkkinen U, Hagen TP. Higher mortality among ACS patients in Finland than in Norway: Do differences in acute services and scale effects in hospital treatment explain the variation? 2017.

[28] Yudi MB, Ramchand J, Farouque O, Andrianopoulos N, Chan W, Duffy SJ, et al. Impact of door-to-balloon time on long-term mortality in high- and low-risk patients with ST-elevation myocardial infarction. Int J Cardiol 2016;224:72-8. doi:10.1016/j.ijcard.2016.09.003. 


\section{Figures captions:}

\section{Figure 1.}

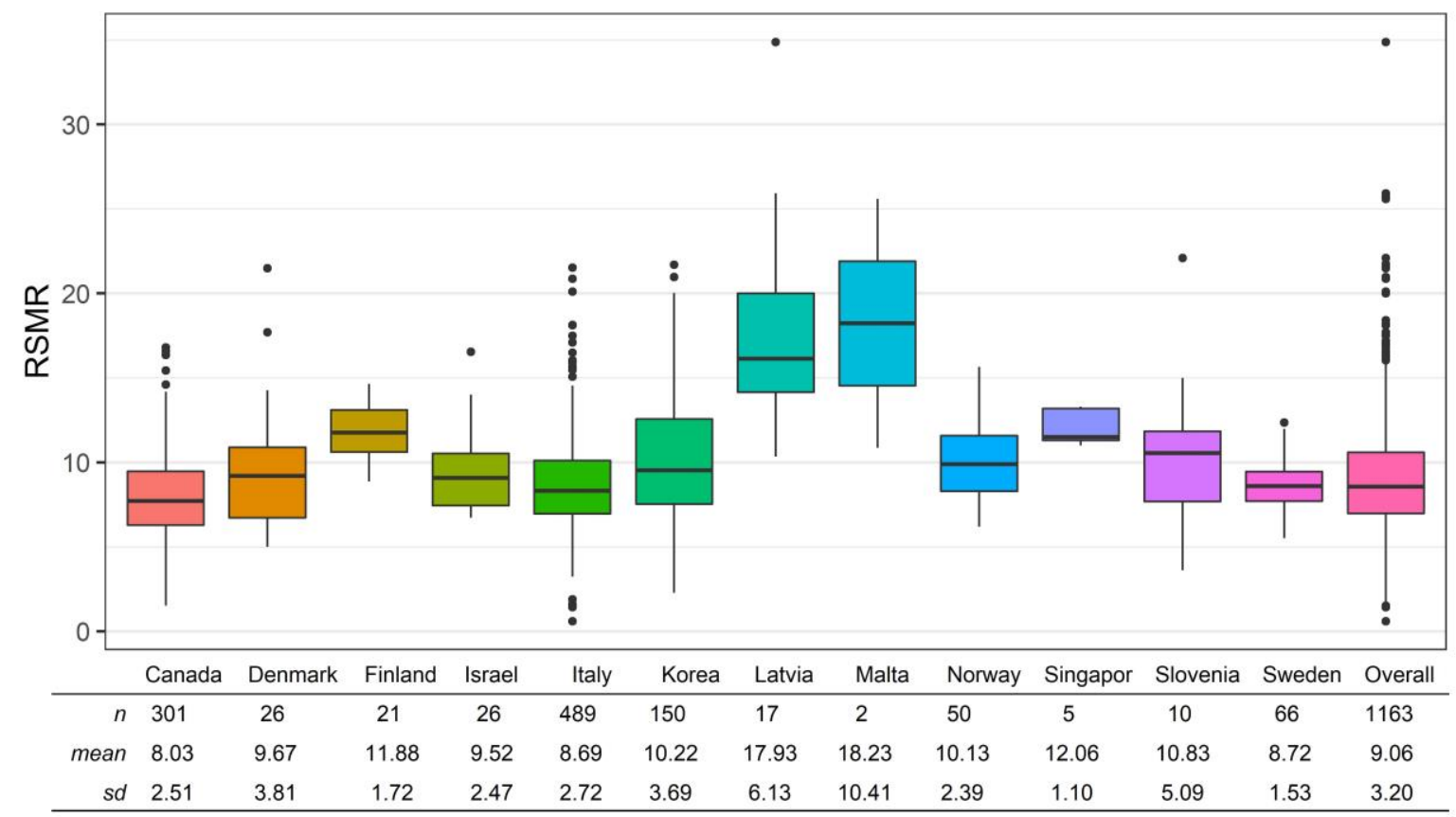

Title: RSMR distribution, by country.

Legend: For a given boxplot, the bar in the middle of the box represents the median value. The top and bottom of the box represent the limits of the first (Q1) and third quartile (Q3). The whole box therefore shows the interquartile range (IQR). The lines (whiskers) outside of the box range from Q1-1.5IQR to Q3+1.5IQR. The dots are "outliers", values outside of this range.

Note: Canadian hospital data were not fully linked to death registries potentially lowering RSMR 
Figure 2.

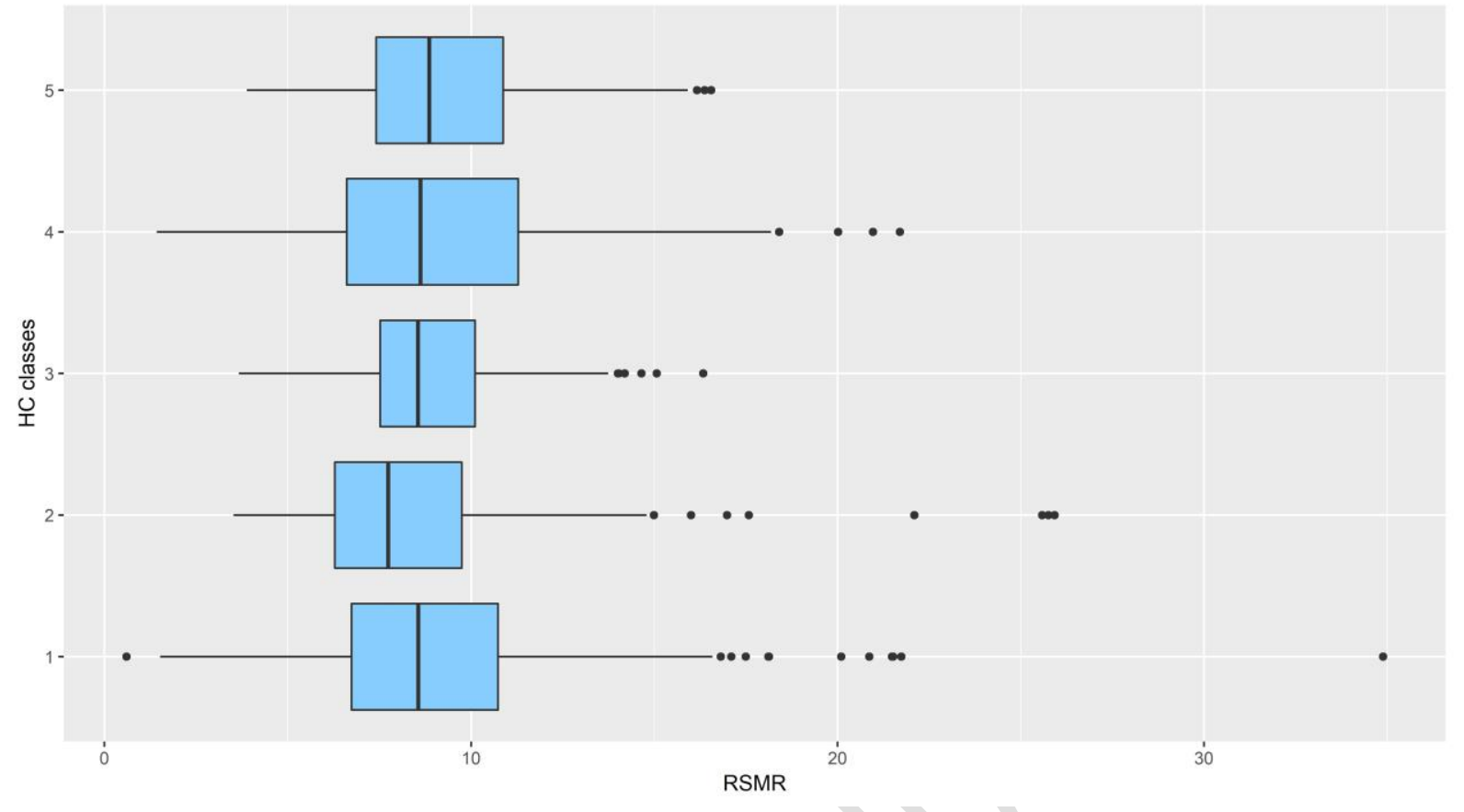

Title: RSMR distribution, by clusters. 
Table 1. Distribution of the hospitals characteristics, overall and by country.

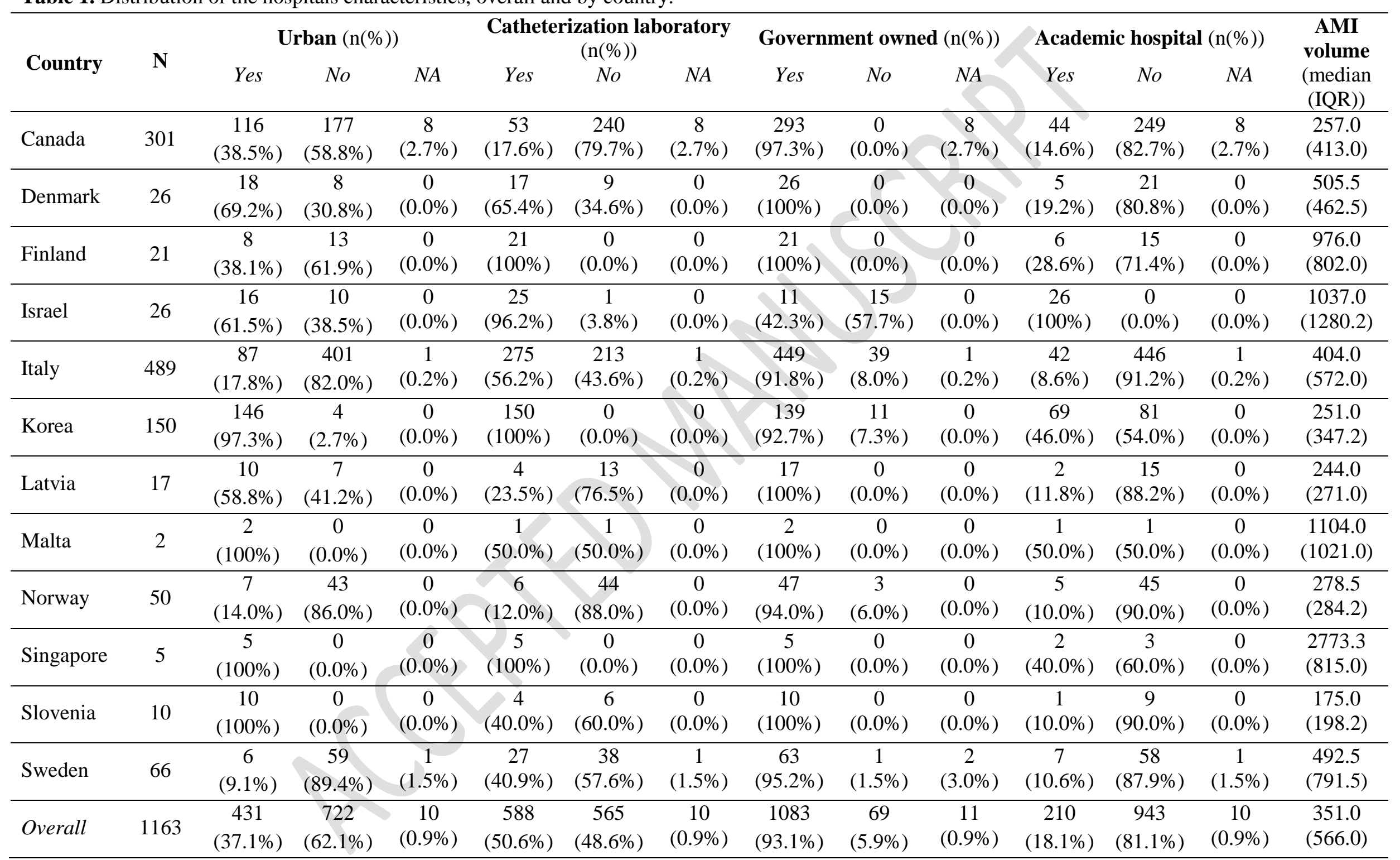


Table 2. Summary of the multivariate linear regression results

\begin{tabular}{|c|c|c|c|c|c|c|c|c|c|}
\hline & & \multicolumn{4}{|c|}{ Model 1 (all characteristics) } & \multicolumn{4}{|c|}{ Model 2 (restricted characteristics) } \\
\hline & & Coef & $95 \% C I$ & $p$ & $V I F^{\mathrm{b}}$ & Coef & $95 \% C I$ & $p$ & $V I F^{\mathrm{b}}$ \\
\hline \multirow[t]{2}{*}{ High volume of $\mathrm{AMI}^{\mathrm{a}}$} & No (ref) & - & - & - & & - & & - & \multirow{2}{*}{2.87} \\
\hline & Yes & -0.83 & $(-1.30,-0.36)$ & $<0.001$ & 1.25 & -1.03 & $(-2.13,0.06)$ & 0.06 & \\
\hline \multirow[t]{2}{*}{ Catheterization laboratory } & No (ref) & - & - & - & & - & & - & \multirow{2}{*}{1.55} \\
\hline & Yes & 0.07 & $(-0.42,0.56)$ & 0.79 & 1.48 & -0.27 & $(-0.78,0.24)$ & 0.30 & \\
\hline \multirow[t]{2}{*}{ Academic } & No (ref) & - & - & - & & - & & - & \multirow[b]{2}{*}{4.01} \\
\hline & Yes & -0.12 & $(-0.66,0.42)$ & 0.67 & 1.27 & -0.76 & $(-2.76,0.96)$ & 0.39 & \\
\hline \multirow[t]{2}{*}{ Urban } & No (ref) & - & - & - & & & & & \\
\hline & Yes & -0.31 & $(-0.78,0.16)$ & 0.20 & & & & & \\
\hline \multirow[t]{2}{*}{ Government owned } & No (ref) & - & - & - & & & & & \\
\hline & Yes & 1.08 & $(0.31,1.85)$ & 0.006 & 1.11 & & & & \\
\hline \multirow[t]{12}{*}{ Country: } & ITA (ref) & - & - & & \multirow{12}{*}{1.05} & - & - & - & \multirow{12}{*}{1.04} \\
\hline & $C A N$ & -0.62 & $(-1.09,-0.14)$ & 0.01 & & -0.63 & $(-1.09,-0.17)$ & 0.007 & \\
\hline & $D N K$ & 1.08 & $(-0.07,2.23)$ & 0.06 & & 1.10 & $(-0.03,2.24)$ & 0.06 & \\
\hline & $F I N$ & 3.16 & $(1.90,4.43)$ & $<0.001$ & & 3.38 & $(2.10,4.65)$ & $<0.001$ & \\
\hline & $I S R$ & 1.61 & $(0.32,2.89)$ & 0.01 & & 0.86 & $(-0.39,2.12)$ & 0.18 & \\
\hline & $K O R$ & 1.80 & $(1.14,2.45)$ & $<0.001$ & & 1.64 & $(1.05,2.23)$ & $<0.001$ & \\
\hline & $L V A$ & 9.30 & $(7.90,10.71)$ & $<0.001$ & & 9.18 & $(7.79,10.58)$ & $<0.001$ & \\
\hline & $M L T$ & 9.97 & $(5.99,13.95)$ & $<0.001$ & & 9.81 & $(5.83,13.80)$ & $<0.001$ & \\
\hline & $N O R$ & 1.46 & $(0.60,2.31)$ & $<0.001$ & & 1.44 & $(0.57,2.31)$ & 0.001 & \\
\hline & $S G P$ & 3.51 & $(0.97,6.06)$ & 0.007 & & 3.48 & $(0.94,6.01)$ & 0.007 & \\
\hline & $S V N$ & 2.37 & $(0.53,4.20)$ & 0.01 & & 2.15 & $(0.36,3.94)$ & 0.02 & \\
\hline & $S W E$ & -0.01 & $(-0.76,0.73)$ & 0.97 & & 0.01 & $(-0.73,0.76)$ & 0.97 & \\
\hline \multicolumn{6}{|c|}{ AMI volume*Catheterization } & 0.55 & $(-0.69,1.81)$ & 0.38 & 3.15 \\
\hline \multicolumn{6}{|l|}{ AMI volume*Academic } & -0.17 & $(-3.38,3.04)$ & 0.92 & 5.92 \\
\hline \multicolumn{6}{|c|}{ Catheterization*Academic } & 1.05 & $(-0.82,2.92)$ & 0.27 & 4.24 \\
\hline \multicolumn{6}{|c|}{ AMI volume*Catheterization*Academic } & -0.48 & $(-3.86,2.89)$ & 0.78 & 6.10 \\
\hline Adjusted $R^{2}$ & $(\sqrt{2+3)}$ & \multicolumn{4}{|c|}{0.22} & \multicolumn{4}{|c|}{0.22} \\
\hline \multicolumn{10}{|c|}{ a $25 \%$ hospitals with the highest AMI volume in each country } \\
\hline \multicolumn{10}{|c|}{${ }^{\mathrm{b}}$ Variance inflation factors } \\
\hline
\end{tabular}


Table 3. Summary of the within country analyses results (regression coefficients for each within country regression)

\begin{tabular}{|c|c|c|c|c|c|c|c|}
\hline & $\begin{array}{l}\text { High volume } \\
\text { of AMI (yes) }\end{array}$ & $\begin{array}{l}\text { Catheterization } \\
\text { laboratory } \\
\text { (yes) }\end{array}$ & $\begin{array}{l}\text { Academic } \\
\text { (yes) }\end{array}$ & $\begin{array}{l}\text { AMI volume } \\
\text {-Catheterization } \\
\text { (interaction) }\end{array}$ & $\begin{array}{l}\text { AMI volume } \\
\text {-Academic } \\
\text { (interaction) }\end{array}$ & $\begin{array}{l}\text { Catheterization } \\
\text {-Academic } \\
\text { (interaction) }\end{array}$ & $\begin{array}{l}\text { AMI volume } \\
\text {-Catheterization } \\
\text {-Academic } \\
\text { (interaction) }\end{array}$ \\
\hline Canada & -0.74 & -1.95 & -0.52 & 2.13 & -0.52 & 1.87 & $\mathrm{NA}$ \\
\hline Denmark & -4.64 & -1.43 & -1.14 & 4.75 & NA & NA & NA \\
\hline Finland & -0.80 & - & -1.15 & - & NA & - & - \\
\hline Israel & -0.84 & 2.74 & - & NA & - & - & - \\
\hline Italy & 2.25 & -0.56 & -0.30 & -2.21 & -0.29 & 0.12 & NA \\
\hline Korea & $-3.88 * *$ & - & 0.13 & - & 1.35 & - & - \\
\hline Latvia & -0.61 & NA & -3.00 & NA & NA & NA & NA \\
\hline \multicolumn{8}{|l|}{ Malta } \\
\hline Norway & -1.69 & -2.13 & 2.01 & NA & $\mathrm{NA}$ & NA & NA \\
\hline \multicolumn{8}{|l|}{ Singapore } \\
\hline Slovenia & 1.22 & -5.48 & 3.78 & NA & NA & NA & NA \\
\hline Sweden & -0.10 & -0.08 & 0.16 & NA & -0.12 & NA & NA \\
\hline Overall & $-1.33 *$ & 0.39 & -1.18 & 0.29 & -0.18 & 1.82 & -0.15 \\
\hline
\end{tabular}

$*: \mathrm{p}<0.05 ; * *: \mathrm{p}<0.01 ; * * *: \mathrm{p}<0.001$

Note: regressions could not be run for Malta and Singapore because of the small number of hospitals 
Table 4. Distribution of the hospitals characteristics, by hospital clusters, and summary of the linear regression results.

\begin{tabular}{|c|c|c|c|c|c|c|}
\hline & & $\begin{array}{c}\text { Cluster } 1 \\
(n=470)\end{array}$ & $\begin{array}{c}\text { Cluster } 2 \\
(\mathrm{n}=101)\end{array}$ & $\begin{array}{c}\text { Cluster } 3 \\
(n=235)\end{array}$ & $\begin{array}{c}\text { Cluster } 4 \\
(n=190)\end{array}$ & $\begin{array}{c}\text { Cluster } 5 \\
(n=167)\end{array}$ \\
\hline \multirow[t]{2}{*}{ Academic: } & Yes & $0(0.0 \%)$ & $16(15.8 \%)$ & $29(12.3 \%)$ & $0(0.0 \%)$ & $165(98.8 \%)$ \\
\hline & $\mathrm{No}$ & $464(98.7 \%)$ & $85(84.2 \%)$ & $205(87.2 \%)$ & $189(99.5 \%)$ & $0(0.0 \%)$ \\
\hline \multirow[t]{2}{*}{ Catheterization laboratory: } & Yes & $0(0.0 \%)$ & $0(0.0 \%)$ & $234(99.6 \%)$ & $189(99.5 \%)$ & $165(98.8 \%)$ \\
\hline & $\mathrm{No}$ & $464(98.7 \%)$ & $101(100 \%)$ & $0(0.0 \%)$ & $0(0.0 \%)$ & $0(0.0 \%)$ \\
\hline \multirow[t]{2}{*}{ Government owned: } & Yes & $452(96.2 \%)$ & $100(99.0 \%)$ & $234(99.6 \%)$ & $146(76.8 \%)$ & $151(90.4 \%)$ \\
\hline & No & $11(2.3 \%)$ & $1(1.0 \%)$ & $0(0.0 \%)$ & $43(22.6 \%)$ & $14(8.4 \%)$ \\
\hline \multirow[t]{2}{*}{ Urban: } & Yes & $3(0.6 \%)$ & $97(96.0 \%)$ & $0(0.00 \%)$ & $170(89.5 \%)$ & $161(96.4 \%)$ \\
\hline & No & $461(98.1 \%)$ & $4(4.0 \%)$ & $234(99.6 \%)$ & $19(10.0 \%)$ & $4(2.4 \%)$ \\
\hline \multicolumn{2}{|l|}{ AMI volume (median) } & 197 & 360 & 737 & 399 & 877 \\
\hline \multicolumn{2}{|c|}{$\operatorname{RSMR}_{(\text {mean})^{\mathrm{a}}}$} & 9.01 & 8.79 & 8.88 & 9.23 & 9.43 \\
\hline \multicolumn{2}{|c|}{ Regression coefficient $(95 \% \mathrm{CI})$} & $-0.42(-0.98,0.15)$ & $-0.64(-1.43,0.16)$ & $-0.55(-1.19,0.08)$ & $-0.20(-0.86,0.47)$ & (ref) \\
\hline \multicolumn{2}{|c|}{ Regression p-value } & 0.15 & 0.12 & 0.09 & 0.56 & (ref) \\
\hline
\end{tabular}

${ }^{a}$ RSMR were not part of the clusters' creation and are show for the reader knowledge

Note: in order to reduce the table size, the "NA" category is not included but remains used for the computation of the percentages 